\title{
Superior sinus venosus atrial septal defect with anomalous pulmonary venous drainage
}

\author{
Stephanie Vella, ${ }^{1}$ Luise Reichmuth, ${ }^{2}$ Stephen Micallef Eynaud, ${ }^{3}$ Alex Manche ${ }^{3}$
}

${ }^{1}$ Department of Medicine, Mater Dei Hospital, Msida, Malta ${ }^{2}$ Medical Imaging Department, Mater Dei Hospital, Msida, Malta

${ }^{3}$ Department of Surgery, Mater Dei Hospital, Msida, Malta

\section{Correspondence to}

Dr Stephanie Vella,

svel0053@gmail.com

Accepted 21 October 2018
Check for updates

(C) BMJ Publishing Group Limited 2018. No commercial re-use. See rights and permissions. Published by BMJ.

To cite: Vella $S$, Reichmuth $L$, Micallef Eynaud S, et al. BMJ Case Rep 2018;11:e225596. doi:10.1136/bcr-2018-

225596

\section{DESCRIPTION}

Sinus venosus defects (SVDs), originally described in 1858 , represent about $2 \%-10 \%$ of all atrial septal defects. ${ }^{1}$ The remainder is composed of ostium secundum (70\%), ostium primum (20\%) and unroofed coronary sinus $(<1 \%)$ defects. Approximately $90 \%$ of SVDs are associated with partial anomalous pulmonary venous return (PAPVR). ${ }^{2}$ The superior SVD (SSVD) variant results from communication between the superior vena cava (SVC)-right atrial (RA) junction and the left atrium and is associated with PAPVR from the right upper lung lobe into the systemic venous circulation. Inferior SVDs are less common and result from anomalous communication of the RA and inferior vena cava (IVC) junction with the left atrium. They are less commonly associated with PAPVR of the right lower lobe pulmonary vein into the IVC.

A 50-year-old woman was found to have a heart murmur during examination as part of a preoperative assessment for a knee replacement. She was asymptomatic and had led an active lifestyle as a basketball player for many years prior to her knee problems. An echocardiogram demonstrated a dilated right ventricle (RV) and good left ventricular systolic function. A multi-gated acquisition (MUGA) scan confirmed the presence of RV dilatation and ECG demonstrated right-bundle branch

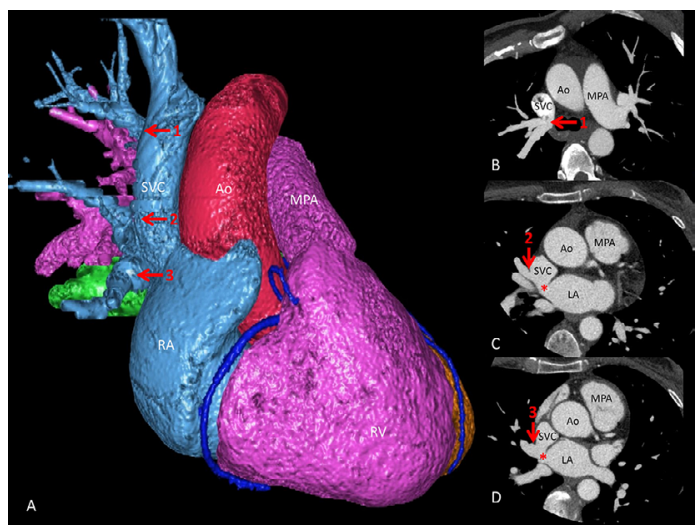

Figure 1 Volume rendered $\mathrm{CT}$ reformat of the heart and great vessels $(A)$ and selected axial maximum intensity projection $C T$ images (B-D) showing the confluence of the superior right pulmonary vein (red arrow 1 ), the accessory right upper pulmonary vein (red arrow 2) and the middle right pulmonary vein (red arrow 3 ) into the superior vena cava (SVC). The superior sinus venosus defect $\left({ }^{*}\right)$, an abnormal communication between the SVC-RA junction and the LA is also seen. Ao, aorta; LA, left atrium; MPA, main pulmonary artery; RA, right atrium; $\mathrm{RV}$, right ventricle.

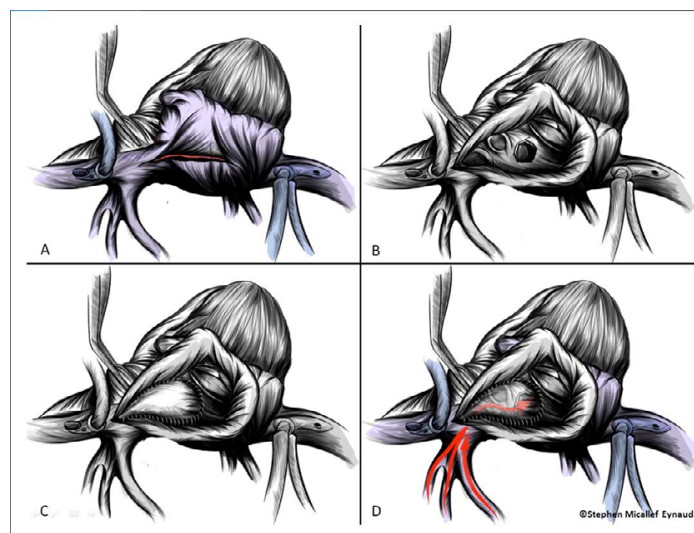

Figure 2 Illustrative images of surgical technique. (A): The superior vena cava (SVC) was cannulated high, above the anomalous venous drainage point and this cannula snared. (B): The SVC was opened longitudinally into the right atrium, avoiding the sinoatrial node region. A vent was placed into the orifice of the right superior pulmonary vein via the SVC in order to facilitate placement of the first patch. The foramen ovale was excised, fashioning an adequate entrance into the left atrium (LA). (C and D): The first patch diverted the pulmonary venous blood into the LA via this opening. Care was taken to allow an adequate lumen beneath this patch, which was sewn in with continuous 5-0 Prolene over the vent, which was removed before completion of this anastomosis. A second pericardial patch was then used to enlarge the SVC to allow unimpeded flow of deoxygenated blood into the right atrium.

block but was otherwise unremarkable. The patient had a family history of heart disease as well as sudden cardiac death and hence initially the possibility of arrhythmogenic right ventricular dysplasia was raised.Cardiac MRI and subsequent CT was performed and revealed an anomalous connection between the SVC-RA junction and the left atrium, representing an SSVD. Note was made of associated partial anomalous pulmonary venous drainage. The right superior pulmonary vein, an accessory right upper and the right middle pulmonary vein were all seen to drain into the SVC high up, close to the innominate vein confluence (figure 1 , videos 1 and 2). Because of this considerable distance from the RA appendage, it was felt that the Warden procedure might result in excessive tension of the anastomosis. A double pericardial patch technique was therefore used (figure 2). The patient made a very good recovery following surgical intervention. Postoperative follow-up echocardiography demonstrated decrease in size of the RV. 


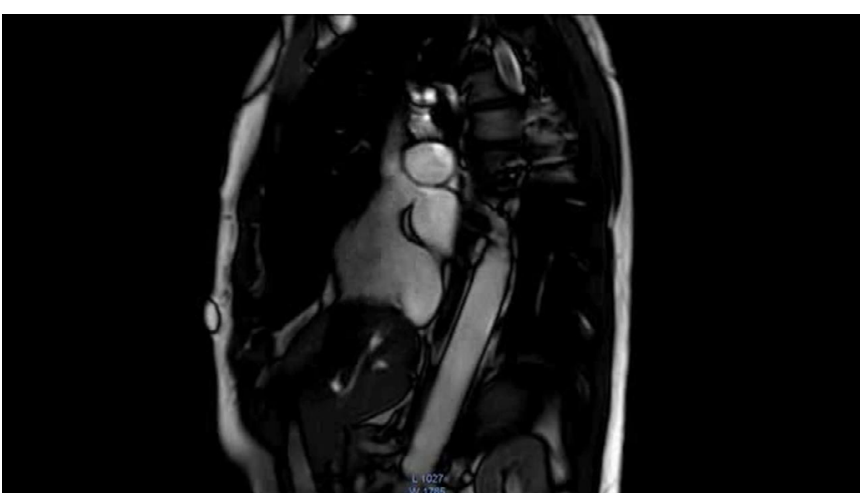

Video 1 Steady-state free precession MRI cine loop of a modified bicaval view showing the superior sinus venosus defect.

Most patients with SSVD are asymptomatic, however, may develop symptoms secondary to arrhythmias or heart failure over time. The clinical implication of such defects is that chronic left to right shunting may result in overload of the right chambers and permanent pulmonary hypertension. Eisenmenger's syndrome occurs with the eventual reversal of this shunt leading to cyanotic right to left shunting. ${ }^{3}$

Due to their anatomical position and the limited available windows for imaging, SVDs are often difficult to visualise on echocardiography, especially if not specifically searched for. Transoesophageal echocardiography is considered superior to transthoracic imaging.

This case highlights the importance of excluding SSVD in unexplained right ventricular dilatation through the use of dedicated cross-sectional cardiac imaging, if no cause is found on echocardiography and to exclude associated PAPVR prior to surgical intervention.

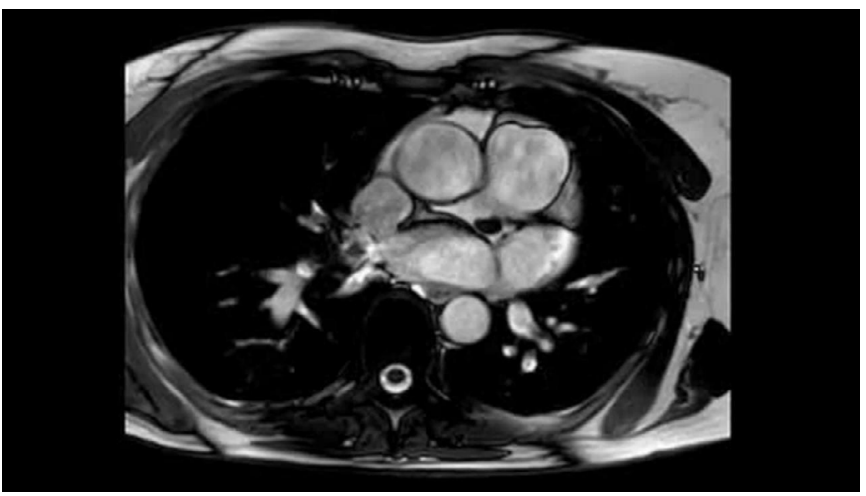

Video 2 Steady-state free precession MRI cine loop of a single slice of an axial stack of the heart at the level of the superior sinus venosus defect.

\section{Patient's perspective}

I had lived all my life with this heart defect without it giving me any problems so I wondered if having the surgery was worth the ordeal. My doctors explained that it was better to undergo the operation when I am fit and healthy rather than in the future when it could result in more complications. As I had recently had my knee replacements, I decided that I might as well go ahead with it. The recovery was thankfully good and I was back to work in just four weeks. The scar bothered me initially especially since it was summertime, but it's thankfully less prominent now.

After the operation my surgeon gave me a presentation to show me what the procedure involved and even though he had explained it to me before, seeing the pictures of open heart surgery was quite frightening and made me consider if I'd actually have gone through with it had I known precisely what it entailed.

\section{Learning points}

- Sinus venosus defects (SVDs) represent $2 \%-10 \%$ of atrial septal defects, which are an important cause of right atrial (RA) and ventricular dilatation and may go undiagnosed until adulthood.

- The superior SVD variant results from communication between the RA-superior vena cava junction and the left atrium and is commonly associated with partial anomalous pulmonary venous return.

- Superior SVDs may be difficult to visualise on transthoracic echocardiography and dedicated cardiac MRI and CT can help in their diagnosis and in the accurate assessment of associated anomalous pulmonary venous drainage prior to surgical correction.

Contributors SV compiled the case report and literature review, interviewed the patient and obtained consent. LR provided the reconstructed images and videos and reviewed the case report. SME provided information regarding surgical technique and accompanying illustrative images. AM provided his expertise on the procedure.

Funding The authors have not declared a specific grant for this research from any funding agency in the public, commercial or not-for-profit sectors.

Competing interests None declared.

Patient consent Obtained.

Provenance and peer review Not commissioned; externally peer reviewed.

\section{REFERENCES}

1 Alpendurada F, Wage R, Mohiaddin R. Evaluation of a sinus venosus atrial septal defect by magnetic resonance: a case report. Rev Port Cardio/ 2008;27:1317-21.

2 Sojak V, Sagat M, Balazova E, et al. Outcomes after surgical repair of sinus venosus atrial septal defect in children. Bratis/ Lek Listy 2008;109:215-9.

3 Rojas CA, El-Sherief A, Medina HM, et al. Embryology and developmental defects of the interatrial septum. AJR Am J Roentgenol 2010;195:1100-4. 
Copyright 2018 BMJ Publishing Group. All rights reserved. For permission to reuse any of this content visit http://group.bmj.com/group/rights-licensing/permissions.

BMJ Case Report Fellows may re-use this article for personal use and teaching without any further permission.

Become a Fellow of BMJ Case Reports today and you can:

- Submit as many cases as you like

- Enjoy fast sympathetic peer review and rapid publication of accepted articles

Access all the published articles

Re-use any of the published material for personal use and teaching without further permission

For information on Institutional Fellowships contact consortiasales@bmjgroup.com

Visit casereports.bmj.com for more articles like this and to become a Fellow 